\title{
The Contribution of Structured Activity and Deliberate Play to the Development of Expert Perceptual and Decision-Making Skill
}

\author{
Jason Berry, ${ }^{1}$ Bruce Abernethy, ${ }^{2,3}$ and Jean Côté ${ }^{4}$ \\ ${ }^{1}$ University of Ballarat, ${ }^{2}$ University of Hong Kong, \\ ${ }^{3}$ University of Queensland, and ${ }^{4}$ Queen's University
}

\begin{abstract}
The developmental histories of 32 players in the Australian Football League (AFL), independently classified as either expert or less skilled in their perceptual and decision-making skills, were collected through a structured interview process and their year-on-year involvement in structured and deliberate play activities retrospectively determined. Despite being drawn from the same elite level of competition, the expert decision-makers differed from the less skilled in having accrued, during their developing years, more hours of experience in structured activities of all types, in structured activities in invasion-type sports, in invasion-type deliberate play, and in invasion activities from sports other than Australian football. Accumulated hours invested in invasion-type activities differentiated between the groups, suggesting that it is the amount of invasion-type activity that is experienced and not necessarily intent (skill development or fun) or specificity that facilitates the development of perceptual and decision-making expertise in this team sport.
\end{abstract}

Keywords: sport expertise, skill development, practice, learning

Skilled perception and decision making are defining characteristics of expert performance in team sports. There is consistent empirical evidence that experts in ball sports are superior in their ability to recognize and recall patterns of play (e.g., Allard, Graham, \& Paarsalu, 1980; Starkes, 1987), to anticipate their opponents' actions (e.g., Abernethy, 1990; Abernethy \& Russell, 1987) and to exploit their opponents' strategic and tactical weaknesses (e.g., McPherson, 1999a, 1999b), yet definitive answers as to how such perceptual and decision-making

\footnotetext{
Berry is with the Essendon Football Club and the School of Human Movement \& Sport Sciences, University of Ballarat, Ballarat, Victoria, Australia; Abernethy is with the Institute of Human Performance, University of Hong Kong, Hong Kong, and the School of Human Movement Studies, University of Queensland, Brisbane, Queensland, Australia; and Côté is with the School of Physical and Health Education, Queen's University, Kingston, Ontario, Canada.
} 
superiority is acquired remain elusive. The overall purpose of this study was to examine the link between developmental experiences in practice, competition, and play and the acquisition of expert perceptual and decision-making skills.

In a significant conceptualization of the development of expertise, Ericsson, Krampe, and Tesch-Römer (1993) proposed that the acquisition of expert performance is a direct and singular function of time spent engaged in a particular type of practice that they termed deliberate practice. Deliberate practice was defined as highly structured practice undertaken with the specific purpose of improving performance in the domain of specialization. In addition, deliberate practice was characterized as requiring sustained cognitive and/or physical effort, being solely directed toward positive skill development and error correction, and being not necessarily inherently enjoyable. On the basis of the practice histories of musicians of different skill levels, Ericsson et al. concluded that individual levels of performance were monotonically related to the amount of solitary (deliberate) practice each had completed. Further, Ericsson et al. reported-consistent with Simon and Chase's (1973) 10-year rule - that at least a decade (equating to some $10,000 \mathrm{hr}$ ) of sustained deliberate practice was required for performance of an elite, international standard to be attained.

The deliberate practice framework has attracted considerable interest with respect to its applicability in the sports domain (see also Ericsson, 1996; Ericsson, 2003). Studies of individual sports, such as wrestling (Hodges \& Starkes, 1996), karate (Hodge \& Deakin, 1998), and figure skating (Deakin \& Cobley, 2003), and team sports, such as soccer and field hockey (Helsen, Hodges, van Winckel, \& Starkes, 2000; Helsen, Starkes, \& Hodges, 1998; Ward, Hodges, Starkes, \& Williams, 2007), have generally confirmed the monotonic relationship between the amount of accumulated practice and level of performance. However, situations have been reported in studies of deliberate practice in sport (e.g., Helsen et al., 2000; Hodges \& Starkes, 1996), in which the amount of time spent in practice with other athletes was equally as important as solitary practice and in which practice time was regarded by the athletes as enjoyable rather than "work-like." These observations were different from those made on the musicians and at odds with aspects of the original definition of deliberate practice. The observation that practice can be intrinsically enjoyable is in accord with the evidence from Côté (1999) that enjoyment or fun is a major determinant for continued participation in sport, even when an athlete is at the peak of their commitment to performance enhancement.

While the need for sustained practice is unquestioned in the pursuit of expert sports performance and while there is empirical support for a number of aspects of the deliberate practice framework, it appears that some other aspects of the framework are problematic and refinements may be needed if it is to fully capture expertise in the sport domain (for a review, see Abernethy, Farrow, \& Berry, 2003). A number of activities that appear pivotal to the development of sports expertise do not constitute deliberate practice, at least as originally defined. Practice activities not performed alone and practice activities that are enjoyable do not meet the original criteria for deliberate practice. Other activities that have been demonstrated to be important for motor skill acquisition, such as observing others perform or engaging in spontaneous fun activity that may lead to incidental learning (e.g., Dickinson, 1978; Kelly, Burton, Kato, \& Akamatsu, 2001) or implicit learn- 
ing (e.g., Maxwell, Masters, \& Eves, 2000), also fall outside the definition of deliberate practice. Perhaps most critically, the strict view of deliberate practice also discounts involvement in competition as a discriminating factor with respect to the acquisition of expertise even though such activities logically provide all the components that any type of practice regimen will seek to improve. Some of the available evidence from team sport indicates that time spent in competition is indeed a pivotal factor in the development of expertise (e.g., Starkes, Deakin, Allard, Hodges, \& Hayes, 1996; see also MacMahon, Helsen, Starkes, \& Weston, 2007). Significantly, expert team sport athletes have reported that they regard competition as the most helpful activity for developing their game-based perceptual and decision-making skills (Baker, Côté, \& Abernethy, 2003a).

In addition to deliberate practice as a contributing factor to expertise, Côté and colleagues (e.g., Côté, 1999; Côté \& Hay, 2002; Côté, Baker, \& Abernethy, 2003,2007 ) have proposed that deliberate play may be an equally important element. Deliberate play activity typically occurs during the sampling years of sport participation (ages 6-13 years), before specialization (approx. ages 13-16 years) and investment (approx. ages 17+ years), and encapsulates developmental physical activities that are intrinsically motivating, provide immediate gratification, and are specifically designed to maximize enjoyment. Deliberate play activity includes the classic neighborhood pickup games, such as park football and street basketball, that are usually played with small-sided teams and flexible peer-defined rules. In contrast to deliberate practice, these deliberate play activities are not partaken with the specific intent of improving performance; however, they nevertheless may become important in influencing whether expertise ultimately appears (Côté, 1999; Côté et al., 2003).

Some recent evidence from team sports suggests that both deliberate practice and deliberate play may contribute significantly to the development of sport expertise, especially in relation to the hallmark skills of perception and decision making (Baker, Côté \& Abernethy, 2003b; Soberlak \& Côté, 2003). Soberlak and Côté (2003) found that elite ice hockey players spent as much time in deliberate play activities as deliberate practice activities before age 20 . In a study of expert decision making in the team sports of basketball, field hockey, and netball, Baker et al. (2003b) noted that, rather than specializing early, expert decision makers specialized relatively late after first experiencing a very broad base of sports in the sampling years. This broad sampling appeared to be functionally important, with the number of sports in which the athletes competed throughout the developmental years being inversely related to the total amount of sport-specific practice then required to attain national team selection in their specialist sport. This finding suggests that some transfer of skills may be possible across sport activities-a contention supported by some studies of pattern recall and recognition transfer (Abernethy, Baker, \& Côté, 2005; Smeeton, Ward, \& Williams, 2004). Importantly, these other competitive sporting experiences, while apparently influential in the development of decision-making expertise, do not fit the deliberate practice notion. The sample of expert decision makers studied by Baker et al. (2003b) also reported participating in a wide range of informal, relatively "unstructured" sport activities during their development-activities more of the nature of deliberate play than deliberate practice. This evidence suggests that there may be multiple pathways to expert performance and alternatives to approaches, favoring early 
specialization, that rely exclusively on the accrual of vast amounts of task-specific deliberate practice (Côté et al., 2007).

Counter to the findings of Baker et al. (2003b), Ward et al. (2007) reported results from a cross-sectional study of English junior soccer players that suggested, from as early as 9 years of age, time spent in deliberate "team" practice was the key variable discriminating elite from subelite players. Although, at least until the under-17 age band, both the elite and subelite players accumulated most hours in playful activities (more overall than in team practice, individual practice, or match play) the accumulated hours spent in these playful activities did not differentiate between the two skill groups. Both the elite and subelite players in the Ward et al. study were found to engage in an equal number of other sports before specializing.

A key limitation in existing studies on the development of expertise is the absence of genuine control groups with comparable playing standards and/or level of sport-specific competitive experience as the experts but lacking the same level of perceptual and decision-making skill. Without such controls it is difficult to satisfactorily de-confound the effects of level of competitive experience from those of perceptual and decision-making expertise. To more fully understand the importance of different types of practice and play activities in the formation of expertise in team sports, there is a need for data derived from players of comparable playing standard and years of experience at the elite level but with clear differences in their degree of within-sport perceptual and decision-making expertise. We report data of this type in this article. Because individual player performance in team sports is determined by multiple attributes and not just perception and decision-making skill (e.g., see Keogh, 1999; Pyne, Gardner, Sheehan, \& Hopkins, 2005), substantial variability in perceptual and decision-making skill can, and does, exist even within a group of elite players. Enhancement of this skill is a perennial concern for elite-level coaches (Farrow, Baker, \& MacMahon, 2007).

This study sought to investigate whether players in the Australian Football League (AFL), subsequently recognized as either expert or less skilled decision makers, differed in their sporting development. Two specific aims were pursued. The first aim was to contrast the relative contribution of experience in structured activities and deliberate play to the development of perceptual and decisionmaking expertise. We included in structured activities all activities in which performance enhancement was the principal purpose and, in deliberate play, all activities principally motivated by goals other than performance enhancement. We predicted, in line with premises within Ericsson et al.'s (1993) deliberate practice notion, that the expert group would have accumulated more hours of experience in structured activities than the less skilled group. We further predicted, in line with the Côté et al.'s deliberate play notion, that the expert group would have also engaged in more hours of experience in deliberate play activities, especially during the sampling years.

The second aim of this study was to ascertain the relative importance of experience in sport-specific activities for the development of perceptual and decisionmaking expertise. A specificity notion would be associated with the prediction that accumulated hours of experience in Australian football would be the best discriminator of the two skill groups; however, based on the work of Baker et al. (2003b), we expected benefits to also accrue from developmental experiences in 
those activities (i.e., invasion-type sports) that share similar perceptual and decision-making requirements with those of Australian football. Thorndike and Woodworth's identical elements theory of transfer (Thorndike \& Woodworth, 1901, cited in Schmidt \& Lee, 2005, p. 454) would suggest that invasion-type activities are more likely to share similar perceptual and decision-making elements with Australian football than other types of games. We predicted that the expert group would show involvement in a greater number of invasion sports and accumulation of more hours of experience in invasion-type activities than the less skilled group, at least up to the end of the sampling years. We further predicted that time spent in invasion-type activities would better predict perceptual and decision-making skill level than time spent in activities of any other type and that hours invested in non-AFL invasion activity during the sampling years would be at least as important as hours invested in AFL-specific activity in discriminating the expert vs. less skilled decision makers.

\section{Method}

\section{Participants and Selection Procedure}

Coaching staff members at each of six professional AFL clubs (Brisbane, Collingwood, Hawthorn, Richmond, Western Bulldogs, and West Coast Eagles) were recruited to help select participants for the study. The coaching staff were provided with lists, from each of the participating clubs, of all current players with the equivalent of one or more seasons of senior AFL football experience. There were some 28-30 players on each list. The staff then independently ranked all the listed players, both from their own club and each of the other five clubs, on their game-based perception and decision-making ability. Perception was operationalized for the coaches in terms of "reading the game" and "moving early to the correct position for the next play," and decision making was explained in terms of "picking the correct option" and "making the right selections."

The rankings followed a set of criteria developed with the assistance and final agreement of three of the AFL coaches. Rankings were pooled across the participating AFL clubs with those players in the top-ranked positions categorized as the expert decision makers and those in the lowest ranked positions categorized as the less skilled decision makers. The three highest ranked and the three lowest ranked players from each participating club were approached by a member of the coaching staff to participate in the study. There was a high level of ranking agreement, with $94 \%$ of all the coaches listing the eventual top-ranked player at each club in their top three decision makers for that club and $79 \%$ listing the eventual bottomranked player at each club in their bottom three decision makers for that club. The overall rankings were confidential for each club and the players were unaware of both the selection procedure and eventual skill groupings.

A total of 17 of the players preclassified as expert decision makers (age: $M=$ 26.4; $S D=3.5$ years) and 15 preclassified as less skilled decision makers (age: $M$ $=24.8 ; S D=2.6$ years) agreed to participate in the study. Given the potential player base across the five clubs of some 176 players, the selected participants within the expert and less skilled groups represented approximately the top and bottom $10 \%$, respectively, of the total ranked sample. Participation in the study 
was voluntary and all players provided informed consent. Importantly, all the participants in the current study, in both the expert and less skilled groups, were regular players in the same elite AFL competition. The participants in the less skilled group were elite players in their own right and the term less skilled relates solely to their perceptual and decision-making skills relative to players in the "expert" group. In the season immediately preceding the study, the mean number of regular season games played, out of the maximum possible of 22, was $18.5(S D=3.7)$ for the participants in the expert group and $15.7(S D=5.1)$ for the participants in the less skilled group. ${ }^{1}$

The expert group first played Australian football at a mean age of 8.3 years $(S D=1.9$ years) and first played in the AFL competition at a mean age of 18.4 years $(S D=1.6$ years). The less skilled group first played Australian football at a mean age of 8.4 years ( $S D=2.0$ years) and first played in the AFL competition at a mean age of 19.0 years ( $S D=1.3$ years). Of the participants in the expert group, eight spent their junior playing years in major cities, two in regional cities, and seven in rural settings or small country towns. In the less skilled group, eight of the participants spent their junior playing years in major cities, four in regional cities, and two in rural settings (cf. Côté, MacDonald, Baker, \& Abernethy, 2006). One player in the less skilled group was born outside of Australia.

\section{Data Collection}

Perception and Decision-Making Task. Each player completed a video-based task designed to assess their perception and decision-making skills and to confirm the group assignments made on the basis of the coaches' rankings. Segments of typical patterns of play, filmed from a wide-angle perspective at AFL games involving teams other than those who provided participants for the study, were used as stimuli for the task and were presented via large screen projection. The task included a total of 19 video segments, each displaying some $15 \mathrm{~s}$ of game footage and each occluded just before the execution of either a handball or a kick pass. The task had two component parts. On the first showing of each video segment, participants were required to recall the position of all players, in both the offensive and defensive teams, as they appeared at the time when the video segment was occluded. This required the participants to mark the individual player positions onto a scaled representation of the scene they had just viewed. Across trials, the total number of players to be recalled ranged from five (three offensive and three defensive players) to 14 (seven offensive and seven defensive players). On the second viewing of 14 of the original 19 video segments, ${ }^{2}$ the participants were required to predict the outcome of the next sequence of play following the moment of occlusion. For this part of the task, the participants were required to mark both the receiving player for the next pass and the impending direction of ball movement.

Interview. Each player participated in an in-depth structured interview based on the Côté, Ericsson, and Law (2005) retrospective recall methodology specifically designed to examine the sporting and related practice histories of elite athletes. The underlying assumption of this method is that the participants will be more accurate and reliable when answering questions based on recall of past episodic experiences rather than when they are forced to infer and reconstruct answers to 
general questions (see also Ericsson \& Simon, 1993). The interviews were conducted in a one-on-one format and each took approximately 90 min to complete, with the participants given the option of an interval break if required. All interviews were conducted by the same interviewer.

The interviews involved the recording, onto a series of developmental charts, of quantitative data reported by the players on their competition, practice, and play activities. The reported activities were categorized into two types-structured activity and deliberate play — on the basis of the reported nature and purpose of the activity. The structured activity category included all those activities that had performance enhancement as their primary focus. Activities involving solitary and small group skills practice (such as kick-to-kick with a partner in Australian football) as well as formal team training were included in this category providing the principal goal was skill improvement. We also viewed involvement in junior competitions as being principally concerned with skill enhancement and consequently also included time spent in such competitions within the structured activity category. Activities categorized as structured therefore included all those meeting the usual criteria for Ericsson et al.'s (1993) deliberate practice plus others such as organized competition.

The deliberate play category, following the definition proposed by Côté (1999), included those activities that were voluntary, intrinsically motivating, and provided immediate gratification. The play activities were generally based on formal sport games or combinations of games, and were guided by peer-defined rules. Examples of the reported deliberate play activities included pick-up games in the park with trees for goals (for Australian football), 3-on-3 half-court challenges with the winning team retaining the court (for basketball), and backyard "Test" matches (for cricket). In terms of structure, deliberate play activities are therefore typically more structured than free play (e.g., Piaget, 1962) but less structured than formally organized activities such as team practices and competition.

The players provided estimates of the number of weeks per year and typical hours per week of involvement in each structured practice and deliberate play activity. Hours spent in each type of activity per year were then derived by multiplying the weekly practice estimates by the number of weeks per year in which the participants engaged in the activity. The number of weeks per year and hours per week reported were dependent on the type of sport or activity in which the participants were engaged, the length of the training and competition periods, and the standard of the competition.

\section{Analyses to Confirm Intergroup Perceptual and Decision-Making Differences}

Assessment of the recall and prediction responses on the perception and decisionmaking task were made using manual matching techniques (cf. Abernethy, Neal, \& Koning, 1994). For the recall portion of the task, a transparent overlay grid with the correct player locations at time of occlusion was created for each of the video segments. Recalled players were identified and matched to the corresponding player locations on the overlay grid. If required, the overlay grid was rotated to maximize the identification of the recalled players according to the inherent 
offensive and defensive patterns. Recall accuracy was recorded as the error between the location of the recalled player and the actual player location. In addition, a standard penalty error, equal to the maximum error possible if the correct player position was located in the center of the scaled representation of the visual display, was added for any errors of omission or commission in each trial. The recall scores were also adjusted for individual scaling error calculated from practice trials in which the participants were required to scale static play scenarios from the video screen to the scaled representation of the playing field. Through this procedure, account was taken of individual differences in the way that some players spread out their representation of the pattern of play on the response sheet, whereas others confine their representation to a smaller area. ${ }^{3}$ A correct response was recorded for the prediction portion of the task if the receiving player and the direction of the next play sequence following occlusion were correctly indicated. One-way ANOVAs were used to test for any between-group differences in both recall and prediction accuracy.

\section{Analyses of Practice History Data}

Categorization of Activities. The reported activities were initially categorized using the games classification model of Thorpe, Bunker and Almond (1986). This model groups games into four major classifications in which the basic strategic and tactical principles are similar within each classification. The four categories are invasion (e.g., soccer, basketball), net/wall (e.g., tennis, squash), field/run scoring (e.g., cricket, baseball), and target (e.g., golf, lawn bowls). Invasion games are those games in which the principal goal is to move into an opponent's territory to score. Australian football, under this classification model, is an invasion game. To allow a full exploration of all the gathered data, a further category (other) was also created to include non-sport-based perceptual-motor interceptive activities such as the playground games of British bulldog, brandy, and poison ball.

Descriptive Analyses. Descriptive statistics on the type and frequency of activities undertaken, along with the total accumulated hours of involvement within structured activity and deliberate play, were calculated for both the expert and less skilled groups. Statistics were also computed for the accumulated hours of involvement within each games classification (e.g., invasion, net/wall, field/run) undertaken separately in structured activity and in deliberate play. Graphical presentation of chronological information was used to help identify peak involvement periods and seek out the presence of any distinct developmental transitions or stages.

Inferential Analyses. The participant sample was necessarily limited in size by virtue of the selection procedures and criteria for defining expertise. In view of the usual considerations in relation to sample type, size, and statistical power, it was therefore only possible to conduct a limited number of inferential analyses. Three main types of analyses were undertaken. First, one-way analyses of variance were used to compare the number of activities each skill group had experienced and the number of hours of experience in different types of structured activities and deliberate play each group had accumulated by the time of first entering the elite AFL competition. Second, independent sample $t$ tests were used to compare the annual 
involvement of the two skill groups in particular activities. Separate comparisons were made at ages 6,12 , and 18 years approximating the commencement of the sampling, specializing, and investment stages identified by Côté (1999) with onetailed tests employed given the a priori expectation of higher scores by the expert group. Third, hierarchical discriminant function analyses were used to determine if the measure of hours spent within each games classification for structured activity or deliberate play could discriminate the expert from the less skilled group. Effect sizes (Cohen's $d$ using pooled standard deviation) were also calculated for each between-group comparison.

For the hierarchical discriminant function analyses, the variables for invasion-type structured activity and invasion deliberate play were given entry priority at Step 1 as it was hypothesized from the existing literature that invasion activities would contribute most to group discrimination (e.g., Abernethy et al., 2005; Baker et al., 2003b; Oslin \& Mitchell, 1998; Thorpe et al., 1986). No a priori hypotheses were formed regarding the relative contribution of the remaining structured activity and deliberate play classification variables to the development of expert decision-making skill and so these variables were entered simultaneously in Step 2. To determine the significance of improvement in classification of the participants from Step 1 to Step 2, McNemar's repeated-measures chi-square was used and jack-knifed classification was employed to provide a more realistic estimate of the ability of the explanatory variables to separate groups (Tabachnick \& Fidell, 2001).

As the majority of the dependent variables of interest were significantly positively skewed, the raw data were first subjected to a logarithmic transformation to satisfy assumptions of normality and checked for multicollinearity before each of the inferential analyses were conducted. An alpha level of .05 was set for all analyses.

\section{Reliability of Reported Information}

Individual playing history information was collated on each of the players from official AFL statistical records (e.g., Lovett, 2001). This information included club of origin, year drafted, level of competition before draft (i.e., junior or senior grade), junior state and national squad selections, year of senior AFL debut, and number of senior AFL games played. As a starting point for the retrospective recall procedure, the playing history information was verified in a systematic manner with each player before the commencement of the main interview. This process informed the participants that their playing history had been researched and this knowledge may help encourage them to recall information accurately (Côté et al., 2005). Importantly, this background information provided a profile of key chronological markers for the player's sport development and helped facilitate the recall of subsequent episodic memories within the interview. This process draws on the critical incident method (Flanagan, 1954) and is similar to the autobiographical memory schedule (Kopelman, Wilson, \& Baddeley, 1989) that has demonstrated a high correlation between recall of factual information and capacity for recollection of episodic experiences.

To assess the credibility of the information provided by the players, followup interviews were conducted independently for a randomly selected subsample 
of four players with one person each player indicated was the most knowledgeable about their development in sport and related activity. In all four cases, the players nominated a parent. The recalled information provided independently by the players and parents was compared with assess convergent validity. Perfect agreement (100\%) was obtained between the number of different structured activities independently reported by the players and their parents. A Pearson productmoment correlation analysis was performed to assess the relationship between the players' estimates of the hours they accumulated within structured activities before entry into the AFL and the corresponding estimates provided by the parents. An $r$ of $0.85(p<.05)$ was obtained, again indicating a high level of agreement between the two sources. It is therefore reasonable to assume that the data set provides an accurate representation of the level of involvement in structured practice for the elite AFL players.

\section{Results}

\section{Perceptual and Decision-Making Performances of the Two Groups}

The expert group significantly outperformed the less skilled group both in recall accuracy, $F(1,29)=4.65 ; p<.05 ; d=0.78$ (Figure 1a), and prediction accuracy, $F(1,28)=5.11 ; p<.05 ; d=0.85$ (Figure $1 \mathrm{~b}$ ), providing objective support for the coaches' differentiation of the two groups on their perceptual and decision-making capabilities. $^{4}$

\section{Involvement in Structured Activity}

Number of Structured Activities. The number of structured activities participated in by the experts $(M=4.41, S D=1.70)$ and by the less skilled players $(M=$ $3.73, S D=1.44$ ) before entering the AFL did not differ significantly, $F(1,30)=$ $1.83, p>.05 ; d=0.47$. Both skill groups demonstrated a similar pattern with respect to the number of different activities in which they were involved at each age (Figure 2a). There were no statistically significant differences between the groups in the number of activities per annum in which they were involved at either ages 6,12 , or 18 years, $t(30)=0.01,0.50$, and -1.06 respectively; all $p s>.05$.

Hours in Structured Activities. The experts accumulated a significantly greater amount of total hours in structured activities before entering the AFL competition $(M=4185, S D=1461)$ than did the less skilled players $(M=3223, S D=927)$, $F(1,30)=4.79, p<.05, d=1.04$. When examined developmentally, both skill groups were seen to have progressively increased their per annum investment in structured activities (Figure 2b). ${ }^{5}$ Neither at age 6, 12, nor 18 years did the per annum investment in structured activities by the expert group significantly exceed that of the less skilled group, $t(30)=0.20,0.77$, and 0.91 respectively; all $p$ s $>$ .05 .

Type and Frequency of Structured Activities. The types of structured activities in which the expert and less skilled players participated during their developing years were generally similar (Table 1). Other than Australian football, basketball, 
(a)

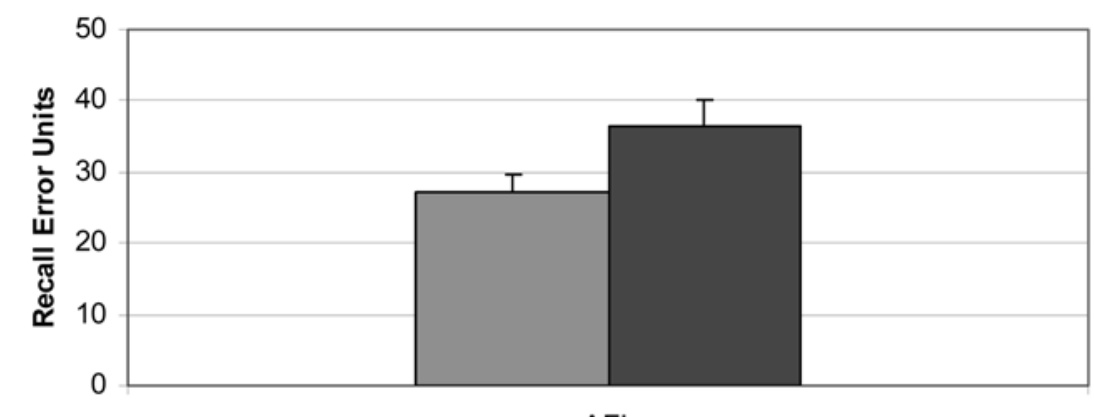

AFL

Experts $\square$ Less-Skilled

(b)

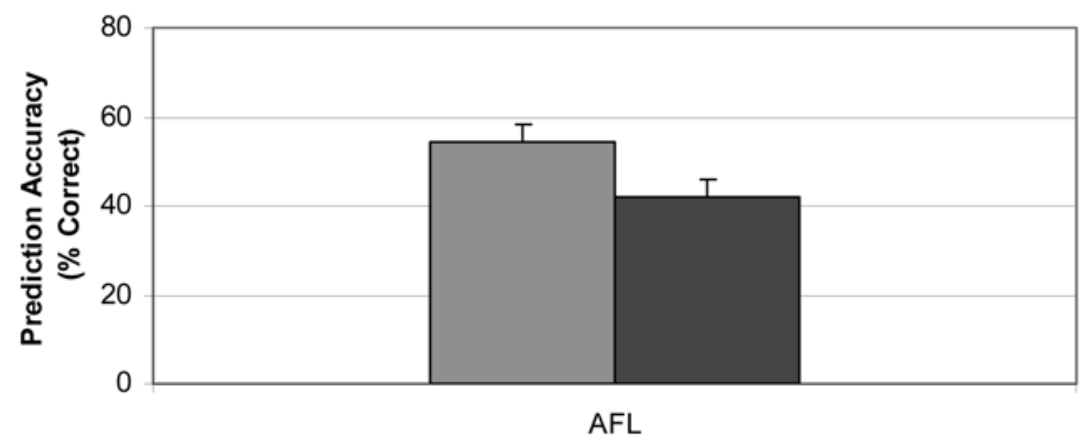

口Experts $\square$ Less-Skilled

Figure 1 - Recall error (a) and prediction accuracy (b) on the perception and decisionmaking task. Values shown are means plus standard errors.

cricket, tennis, and athletics were the sports in which the players most frequently participated as juniors.

Hours in Structured Activity Within Different Game Classifications. Inspection of the hours accumulated within specific games classifications revealed that, by the time of first entering the AFL competition, both the expert and less skilled groups spent more hours of involvement within invasion game activity than in either net/wall, field/run-score, target, or other sports (Figure 3). Experts $(M=$ $3279, S D=1503$ ) also accumulated a greater number of hours of involvement 
(a)

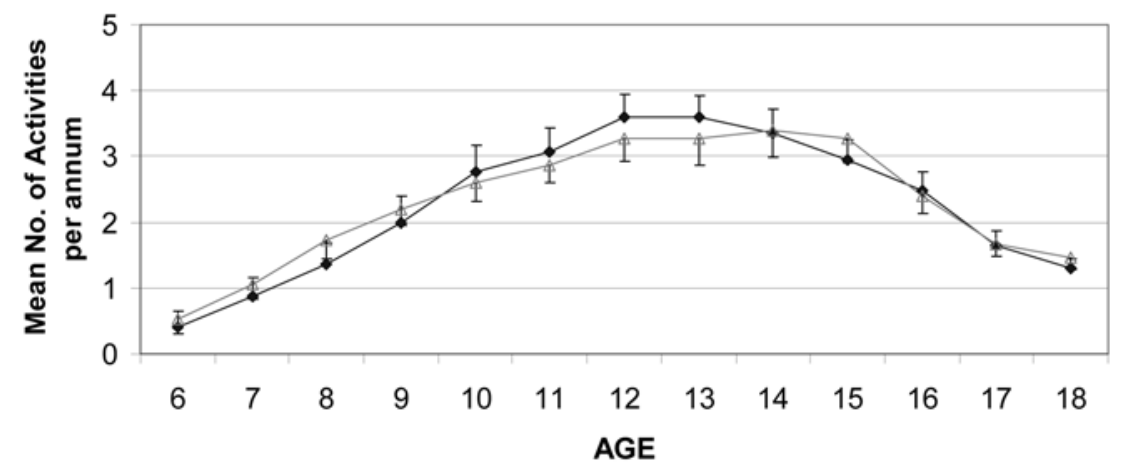

- Experts $\triangle$ Less-Skilled

(b)

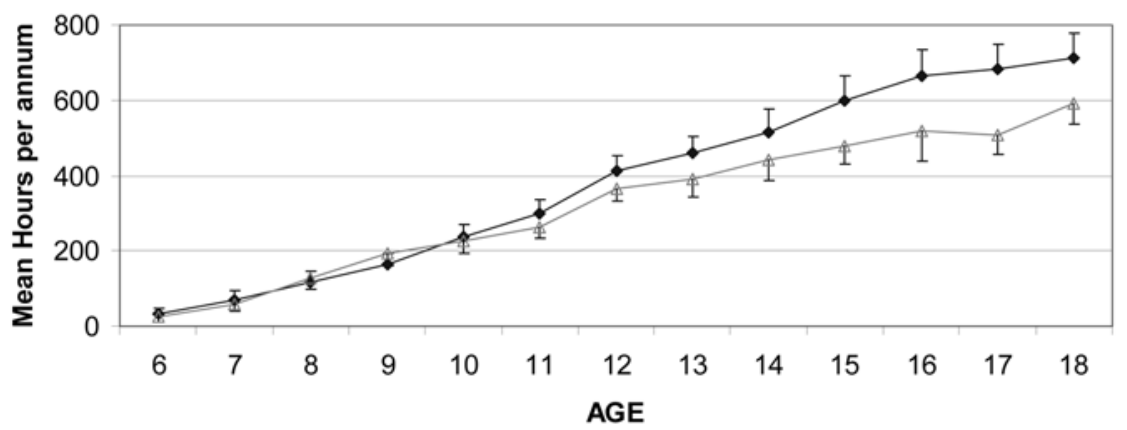

Experts $\triangle$ Less-Skilled

Figure 2 - Number of structured activities per annum (a) and hours invested in these activities (b) as a function of age. Note: Total hours of involvement within structured activities includes both the time invested in training (solitary and group) and competition. Values shown are means plus standard errors.

within invasion sports than did the less skilled players $(M=2287, S D=859), F(1$, $30)=4.90, p<.05 ; d=1.15$. Hierarchical discriminant function analysis with hours accumulated in invasion sport as a predictor of group membership resulted in a significant discriminant function at Step $1, \Lambda=856 ; F(1,30)=5.06, p<.05$. Hours in invasion sport explained $14.35 \%$ of criterion variance and correctly classified the perceptual/decision-making skill level of $65.6 \%$ of the participants (compared with $50.0 \%$ who would be correctly classified by chance alone). The McNemar test showed the addition of the hours spent in other game types in Step 2 of the analysis did not significantly contribute to the accuracy of group 


\section{Table 1 Structured Practice and Deliberate Play Activities Reported by}

Each Skill Group

\begin{tabular}{cllllll}
\hline & & \multicolumn{2}{c}{ Experts } & & \multicolumn{2}{c}{ Less Skilled } \\
\cline { 4 - 6 } \cline { 5 - 6 } Category & Rank & Activity & Frequency & & Activity & Frequency \\
\hline Structured & 1 & Australian football & $100 \%$ & & Australian football & $100 \%$ \\
practice & 2 & Basketball & $82 \%$ & & Basketball & $67 \%$ \\
& 3 & Cricket & $82 \%$ & & Cricket & $60 \%$ \\
& 4 & Tennis & $65 \%$ & & Tennis & $53 \%$ \\
& 5 & Athletics & $35 \%$ & & Athletics & $47 \%$ \\
& 6 & Soccer & $18 \%$ & & Surf-life saving & $13 \%$ \\
\hline Deliberate & 1 & Basketball & $65 \%$ & & Basketball & $53 \%$ \\
play & 2 & Cricket & $53 \%$ & & Cricket & $47 \%$ \\
& 3 & 4 Square & $47 \%$ & & British bulldog & $40 \%$ \\
& 4 & Australian football & $35 \%$ & & Keepings-off & $27 \%$ \\
& 5 & British bulldog & $24 \%$ & & Australian football & $20 \%$ \\
\hline
\end{tabular}

Note. Frequency values represent the percentage of players in each skill group who reported participating in each activity. Australian football, basketball, tennis, and soccer are categorized as invasion games, tennis as net/wall, and cricket as field/run score. All remaining activities were classified as other.

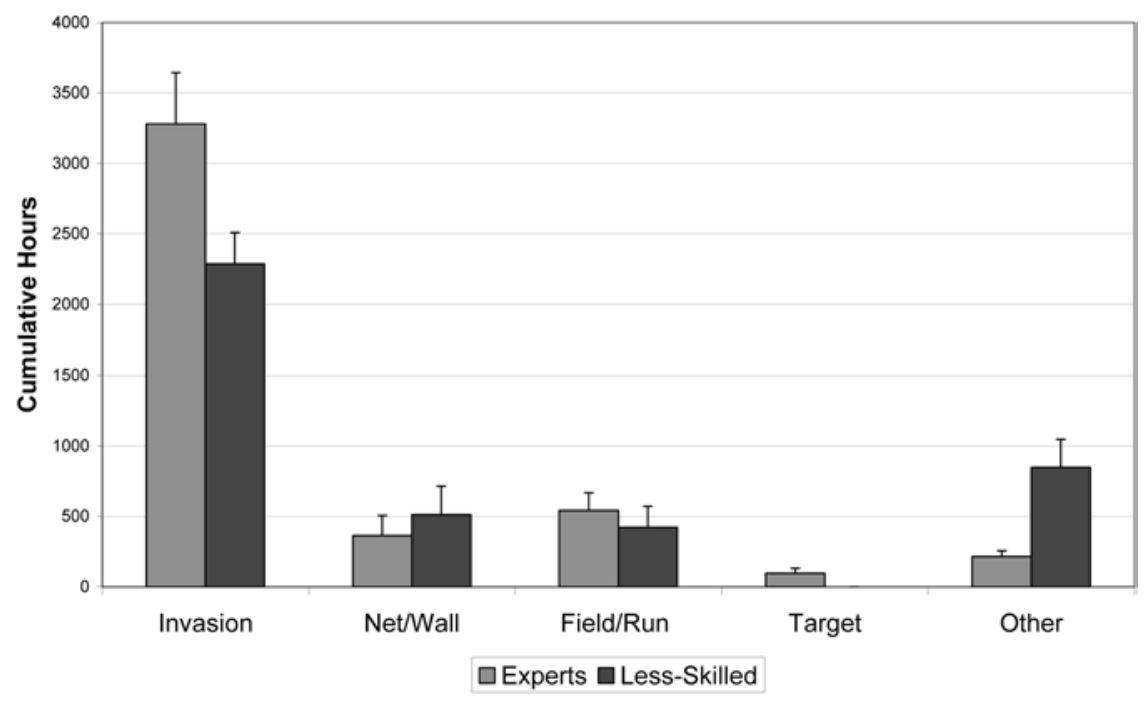

Figure 3 - Accumulated hours in structured activity per games classification at the time of entry into the AFL. Values shown are means plus standard errors. 
membership prediction over and above that achieved with invasion sport activity alone, $\chi^{2}(1)=0.00, p>.05$.

Hours in Australian Football-Specific Structured Activity. Hours spent in Australian-football-specific training and competition activity was a major contributor to the invasion sport activity reported in Figure 3; however, the hours accumulated in Australian-football-specific structured activity before entering the AFL competition did not differ significantly between the experts $(M=2510, S D=1079)$ and the less skilled players $(M=2025, S D=788), F(1,30)=1.43, p>.05 ; d=0.62$. The skill groups did not differ in the overall pattern of accumulated hours in Australian-football-specific structured activity when this measure was examined chronologically (Figure 4) and no group differences in the hours committed per annum to this type of practice were evident at either the 6,12 , or 18 year ages, $t(30)=-0.42,1.45$, and 1.58 respectively; all $p s>.05$.

\section{Involvement in Deliberate Play}

Number of Deliberate Play Activities. The number of deliberate play activities experienced by the experts $(M=4.18, S D=2.24)$ and by the less skilled players $(M=3.53, S D=1.81)$ by the age of entering the AFL competition did not differ significantly, $F(1,30)=0.93, p>.05 ; d=0.36$. The number of deliberate play activities undertaken per annum (see Figure 5a) also did not differ between the groups at ages 6,12 , or 18 years, $t(30)=1.00,1.62$, and -1.64 respectively; all $p \mathrm{~s}$ $>.05$.

Hours in Deliberate Play Activity. The total hours accumulated in deliberate play activities before entering the AFL competition did not differ between the experts $(M=2210, S D=1999)$ and the less skilled players $(M=1124, S D=$ $1036), F(1,30)=2.63, p>.05 ; d=1.05$. The experts reported a greater mean time

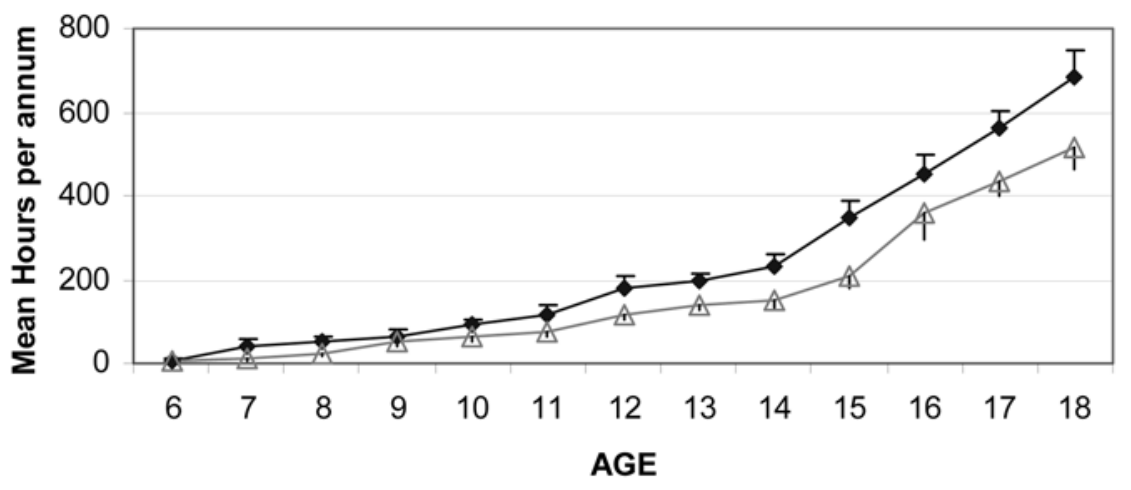

$\multimap$ Experts $\triangle$ Less-Skilled

Figure 4 - Hours invested per annum in Australian-football-specific structured activity as a function of age. Values shown are means plus standard errors. 
(a)

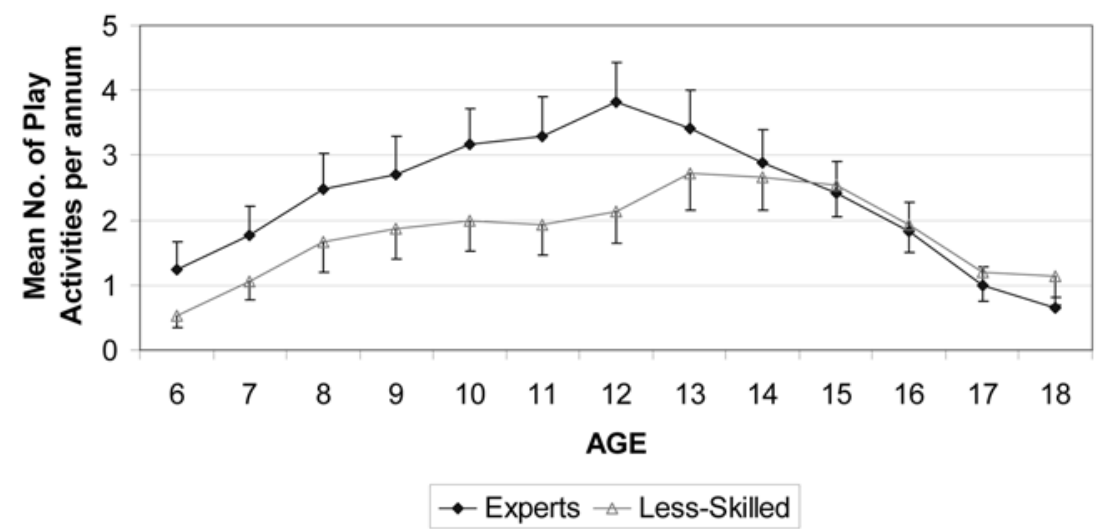

(b)

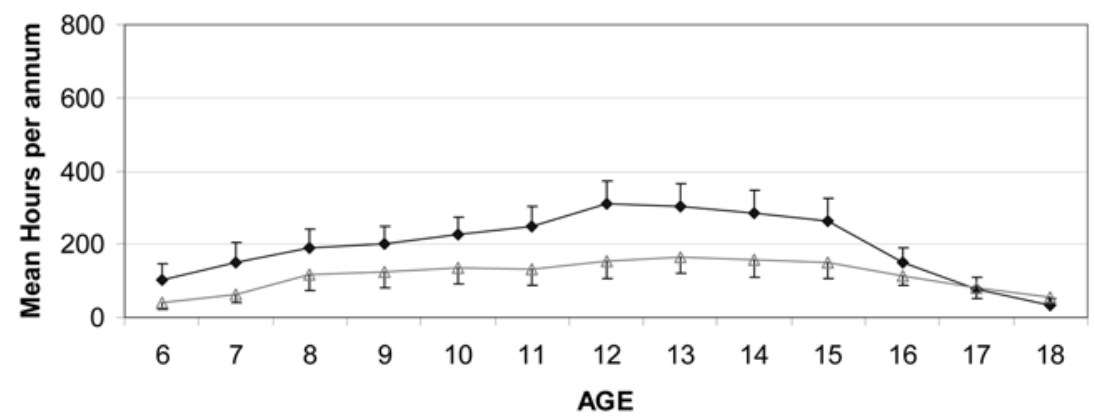

Experts $\triangle$ - Less-Skilled

Figure 5 - Number of deliberate play activities per annum (a) and hours invested in these activities (b) as a function of age. Values shown are means plus standard errors.

commitment to deliberate play activity per annum at age $12, t(30)=2.48, p<.05$; $d=0.86$, but not at either age $6, t(30)=0.61, p>.05$, or 18 years, $t(30)=-0.97$, $p>.05$ (Figure 5b).

Type and Frequency of Deliberate Play Activities. Basketball and cricket were the most frequently reported deliberate sport play activities reported by both skill groups (Table 1). Of particular interest is the relatively low frequency of Australian-football-specific deliberate play activity reported by both skill groups. 
Hours in Deliberate Play Within Games Classification. Analysis of the hours accumulated in specific games classifications revealed that by the time of entry into the AFL competition the experts had spent more hours than the less skilled players within invasion deliberate play activity $(M=1039, S D=977 ; M=328, S D$ $=433$, respectively), $F(1,30)=6.76, p<.05 ; d=1.64$ (Figure 6). Hierarchical discriminant function analysis with hours accumulated in invasion play activities as a predictor of group membership resulted in a statistically significant discriminant function at Step $1, \Lambda=815 ; F(1,30)=6.80, p<.05$. Hours in invasion play activity explained $18.49 \%$ of the criterion variance and correctly classified $65.6 \%$ of the participants. As in the previous discriminant analysis for structured practice activity, the McNemar test showed the addition of the net/wall, field/run, target, and other play variables in Step 2 of the analysis did not significantly contribute to the accuracy of group membership prediction over and above that obtained from invasion play activity alone, $\chi^{2}(1)=0.00, p>.05$. In addition, all variables other than hours in invasion play activity exhibited low correlations with the discriminant function.

Hours in Australian Football-Specific Deliberate Play. Ten of the 17 participants within the expert group and 3 of the 15 participants within the less skilled group reported undertaking AFL deliberate play activity during their developing years. The accumulated hours invested by the expert group on this type of activity $(M=449, S D=802)^{6}$ did not differ significantly from those invested by the less skilled players $(M=135, S D=293), F(1,30)=1.73, p>.05 ; d=1.06$. Australianfootball-specific deliberate play was a modest contributor to the total hours accu-

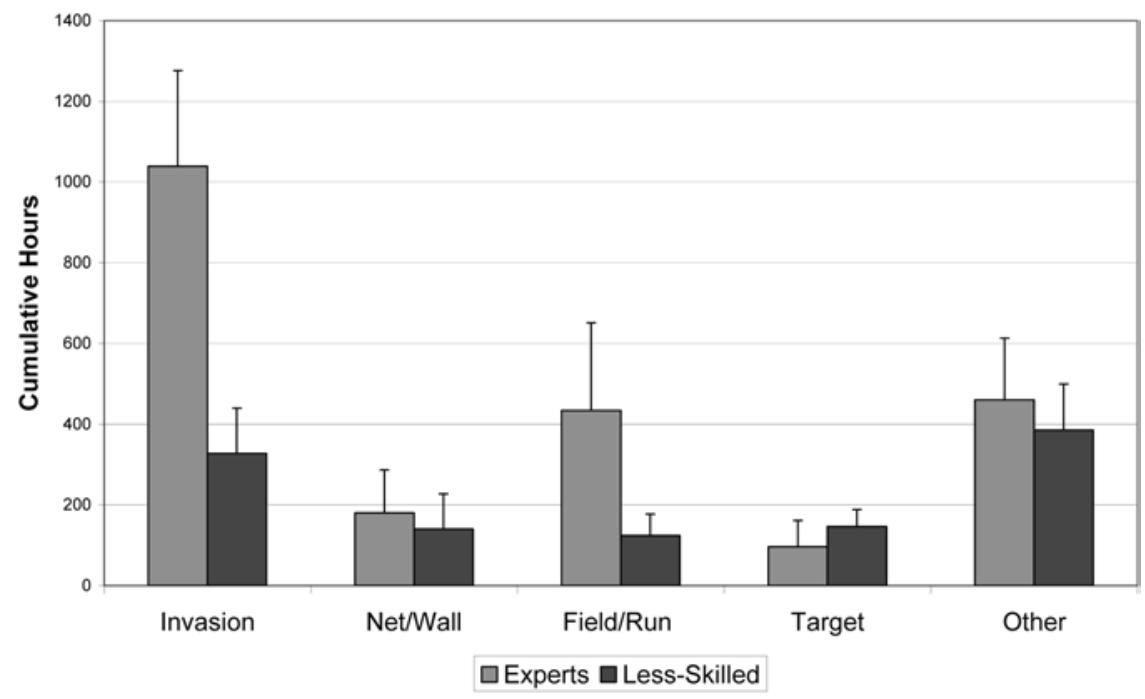

Figure 6 - Accumulated hours in deliberate play activity per games classification at the time of entry into the AFL. Values shown are means plus standard errors. 
mulated in deliberate play, accounting for $20.3 \%$ of all deliberate play hours for the experts and $12.0 \%$ for the less skilled group. In contrast, activities specific to Australian football accounted for $52.1 \%$ and $62.8 \%$, respectively, of all hours accumulated in structured activity by the expert and less skilled groups.

\section{Involvement in All Types of Invasion Activities}

Given the predominant position of invasion-type activities in both the analysis of structured activities and deliberate play, follow-up analyses were conducted to explore the significance of overall experience in invasion activities in the development of perceptual and decision-making skill in Australian football. All invasion activity identified within the games classification model was combined for these analyses across both structured activity and deliberate play.

Number of Invasion Activities. Overall, the experts $(M=3.59, S D=1.37)$ participated in significantly more invasion activities up to the age of entering the AFL elite competition than did the less skilled players $(M=2.53, S D=0.92), F(1,30)$ $=6.09, p<.05 ; d=1.15$. The number of invasion activities that were reported per annum was significantly greater for the experts at age 12 years, $t(30)=1.76, p<$ $.05 ; d=0.63$, but not at the ages of 6 or 18 years, $t(30)=0.94$ and -0.26 respectively; all $p s>.05$ (Figure 7a).

Hours in Invasion Activity. The experts had accumulated significantly more hours within invasion activity than had the less skilled players by the time they entered the AFL competition $(M=4319, S D=1613 ; M=2615, S D=794$, respectively), $F(1,30)=12.60, p<.05 ; d=2.14$. At age 12 years, the experts were undertaking some $200 \mathrm{hr}$ of additional invasion activity per annum compared with the less skilled players, $t(30)=3.67, p<.05 ; d=3.91$ (Figure $7 \mathrm{~b}$ ). The per annum investment in invasion activity did not differ between the two groups at age 6 , $t(30)=0.72, p>.05$, or age 18 years, $t(30)=1.56, p>.05$.

Hours in Australian Football. The hours accumulated in Australian football before entering the AFL competition did not differ significantly between the experts $(M=2959, S D=1223)$ and the less skilled players $(M=2160, S D=700)$, $F(1,30)=4.96, p<.05 ; d=1.14$. Examined developmentally, the amount of time devoted per annum to Australian-football-specific invasion activity was significantly greater for the expert group at age $12, t(30)=2.59, p<.05 ; d=1.96$, but not at age $6, t(30)=0.28, p>.05$, or 18 years, $t(30)=1.57, p>.05$ (Figure 8a).

Hours in non-Australian-Football Invasion Activity. The experts accumulated approximately three times as many hours of involvement in non-Australian-football invasion activity than did the less skilled players by the time of entering the AFL competition $(M=1359, S D=1422 ; M=445, S D=444$, respectively). Even though the total hours accumulated in non-Australian-football invasion activity were far less than those reported for Australian football, clear skill group differences were apparent, $F(1,30)=6.98, p<.05 ; d=2.06$. The experts reported a significantly greater number of hours per annum in non-Australian-football invasion activity at age 12 years, $t(30)=2.79, p<.05 ; d=2.29$, but not at ages $6, t(30)$ $=1.10, p>.05$, or 18 years, $t(30)=0.12, p>.05$ (Figure $8 b)$. 
(a)

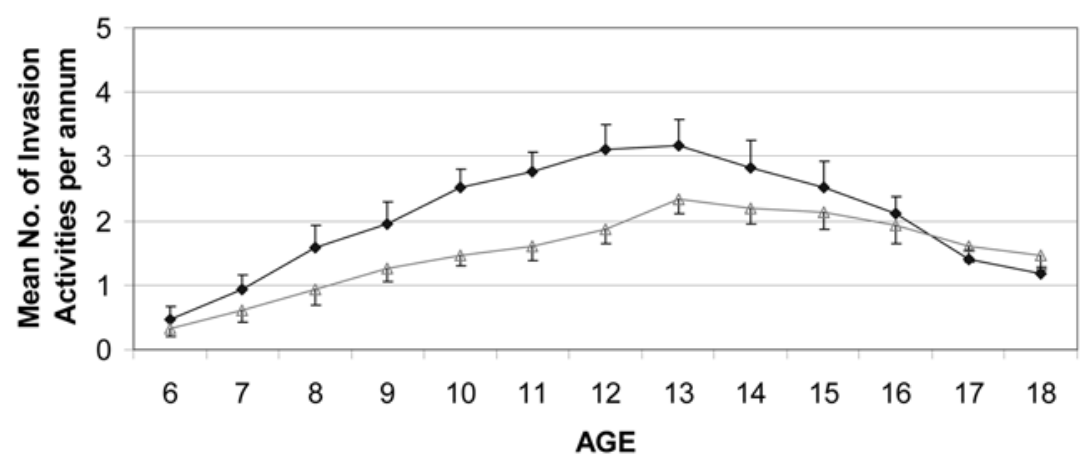

Experts $\triangle$ Less-Skilled

(b)

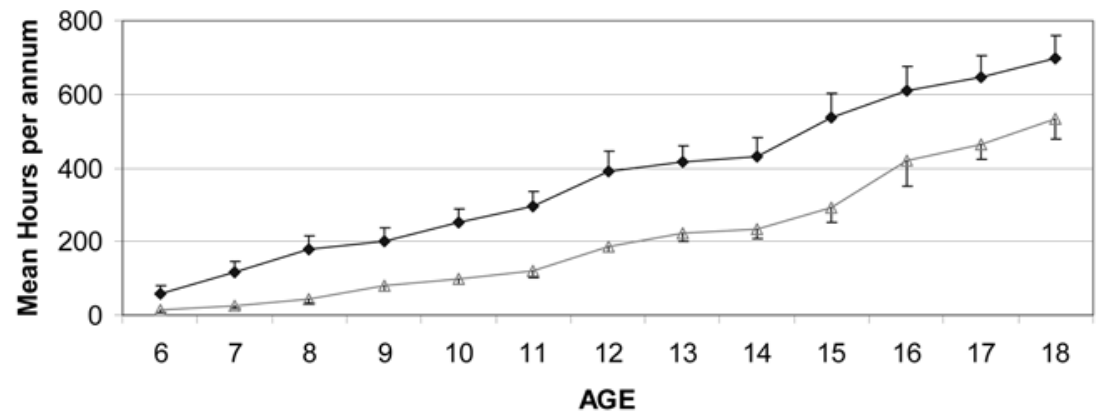

Experts $\triangle$ - Less-Skilled

Figure 7 - Number of invasion activities per annum (a) and hours invested in these activities (b) as a function of age. Values shown are means plus standard errors.

\section{Discussion}

We examined the developmental histories of two groups of players from within the same elite AFL competition-a group considered by their coaches and peers as expert decision makers and a group considered to be less skilled decision makers. Following confirmation, via laboratory tasks, that the groups indeed differed systematically in their perceptual and decision-making skills in a manner consistent with the coaches' rankings, the investigation sought to reveal those practice, competition, and play experiences that best differentiated the two groups. Systematic developmental differences were apparent between the groups even though they were derived from the same elite cohort of players competing at the highest level of competition within their sport. 
(a)

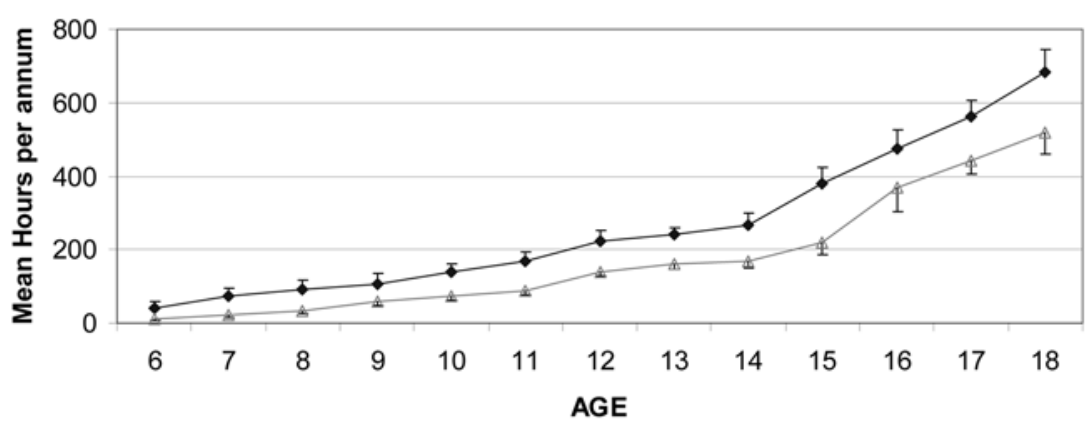

Experts $\triangle$ - Less-Skilled

(b)

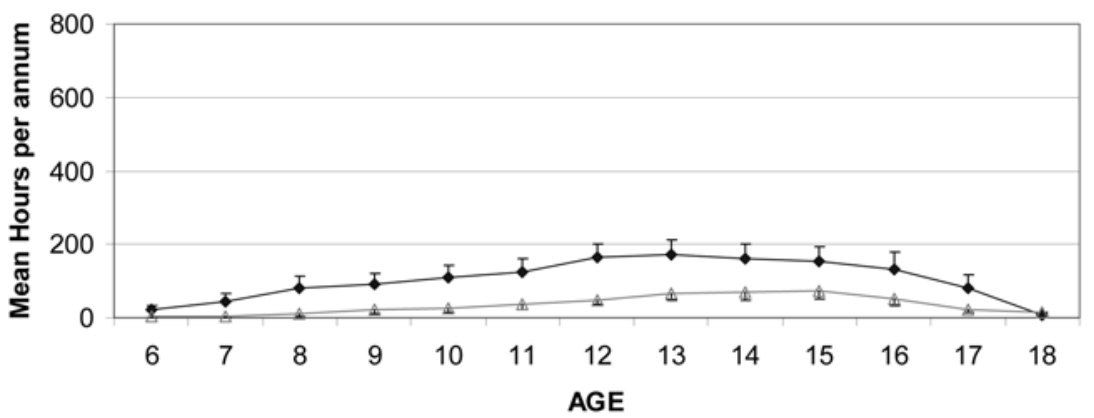

Experts $\triangle$ - Less-Skilled

Figure 8 - Hours invested per annum in invasion activities that are (a) specific to Australian football and (b) not specific, expressed as a function of age. Values shown are means plus standard errors.

Our first aim was to determine the relative contributions of structured activities and deliberate play to perceptual and decision-making expertise. In relation to the prediction derived from the notion of deliberate practice (Ericsson et al., 1993), it was found that the expert and the less skilled decision makers did not differ in the numbers of structured activities in which they participated throughout their developing years but the experts committed a greater amount of time to these activities. By the time of entering the AFL, the accumulated hours of experience in structured activities was significantly greater for the expert group. Both groups recalled investing more time in structured invasion-type activities than in other types of games; however, the expert decision makers demonstrated significantly more investment in structured invasion practice than did their less skilled counterparts. Hours spent in invasion sports significantly discriminated the expert from the less skilled decision makers. While these data do not permit distinction 
between hours spent in deliberate practice (as defined by Ericsson et al., 1993) and hours spent in competition and other types of structured activity, the evidence collected on structured activities in this study is nevertheless consistent with the prevailing view that the amount of practice devoted directly to activities designed to specifically improve skill is an important determinant of the emergence of expertise (Ericsson et al., 1993; Hodge \& Deakin, 1998; Hodges \& Starkes, 1996). The level of involvement by the expert group by age 18 in all structured activity $(\sim 4,200 \mathrm{hr})$, and in structured activity specifically in Australian football $(\sim 2,500$ $\mathrm{hr}$ ), was well below the $10,000 \mathrm{hr}$ of deliberate practice suggested by Ericsson et al. (1993) as necessary for winning at an international level of competition but was in line with the number of practice hours reported in other studies of expert team sport players (Baker et al., 2003b; Helsen et al., 1998; Soberlak \& Côté, 2003).

In relation to the prediction derived from Côté's notion of deliberate play (e.g., Côté, 1999; Côté \& Hay, 2002; Côté et al., 2007), some differences were also evident between the two skill groups in their involvement in deliberate play. Whereas the number of deliberate play activities and the accumulated hours of deliberate play before entering the AFL competition did not differ between the two groups, the per annum commitment of time to deliberate play activities toward the end of the sampling years (tested at age 12 years) did differ reliably between the two groups and in the predicted direction of greater commitment by the expert group. The hours invested in invasion-type deliberate play was found to be a reliable discriminator of the two skill groups, with expert decision makers accumulating significantly more than their less skilled counterparts.

Taken together, the evidence from the two different types of sport activity suggests that even though investment in structured activities is important for developing sport expertise, the time commitment to involvement in structured activity is not the only factor that reliably distinguishes the expert decision makers from their peers (see also Starkes, 2000). Hours spent in deliberate play activities, especially invasion-type deliberate play, during the sampling years may be equally discriminative. Notably, the effect sizes for comparisons between the two skill groups on the accumulated hours spent in structured practice activities and on the accumulated hours spent in deliberate play activities up to entering the AFL were almost identical.

Our second aim was to determine the importance of experience in sport-specific activities for the development of perceptual and decision-making expertise and examine the extent to which involvement in activities other than Australian football was beneficial. Only weak support was found to support a prediction that the extent of experience specifically in Australian football was the root cause of the differences in perceptual and decision-making skill between the two groups. No group differences were evident in the accumulated hours of Australian football experienced in either structured settings, in deliberate play, or summated across both settings. This is not, of course, to suggest that specific experience in Australian football is not critical to skill development in this sport but simply to indicate that the benefits such experience provides are not principally responsible for the differences in perceptual and decision-making skill evident among elite players. 
A greater level of support was forthcoming to support the view that some transfer of learning is possible across different types of activities and that experience in activities other than, or additional to, Australian football is beneficial for the development of expert perception and decision making. Consistent with the findings of Baker et al. (2003b), a number of lines of evidence were found to indicate that the extent of experience in those activities that share perceptual and decision-making requirements similar to those of Australian football (i.e., invasion sports) is particularly important. First, both the total number of invasion activities experienced before entering the AFL and the number of invasion activities undertaken per annum at age 12 (during the sampling years) were significantly greater for the expert group. Interestingly, the groups did not differ on the total number of activities of all types experienced in either structured settings or as deliberate play, indicating that less skilled group were more involved in activities that did not have an invasion emphasis. Second, the two groups were clearly discriminated by the accumulated hours in invasion-type activities. This was true regardless of whether it was structured activities or deliberate play under examination. Activities of a type other than invasion did not add significantly to the skill group discrimination provided by consideration of only invasion-type activities. Third, hours invested in invasion activities other than Australian football, but not hours invested specifically in Australian football, were significantly different between the two groups. While the total number of hours invested in Australian football was much greater than that invested in other types of invasion activity, at least among this elite cohort of AFL players, it was the time spent in invasion activities outside of the sport of specialization that appeared especially critical in helping establish an expert advantage in perception and decision making.

Overall, this study demonstrates that among elite players the nature of the developmental experiences of the players may exert an enduring influence on the acquisition of expert perception and decision-making skills. Expert decision makers in Australian football have been shown to reliably differ from peers who are demonstrably less skillful in perception and decision making by the variety and amount of exposure they have had to invasion activities. By the time they enter the AFL, expert decision makers have spent more time in both structured and deliberate play activities in all invasion sports than less skilled decision makers, suggesting it is the involvement in the perceptual and decision-making requirements of invasion activities per se and not whether such activity is partaken principally for fun (as in deliberate play) or principally for the instrumental purpose of improving skill (as in deliberate practice) that is critical. Experts appear to gain particular benefit from experience in invasion activities in sports other than Australian football, thus suggesting, consistent with Smeeton et al. (2004) and Abernethy et al. (2005), that some transfer of perceptual and decision-making skills across sports is possible. These findings may provide a valuable source of information to guide the design of player development and participation strategies within a wide range of invasion sports although additional work is obviously needed to determine that extent to which these findings may be culture, system, or sport dependent. Even for players at the highest level of competition, there is clearly potential to improve perception and decision making through the provision 
of appropriate practice experiences and, through this, improve the overall skills and potential for success of individual players.

\section{Notes}

1. Two of the participants had not played any games in the preceding season due to injury. The number of regular season games played was not significantly different between the two skill groups, $t(28)=1.77, p>.05$.

2. Five of the video segments used for the recall task were excluded from the prediction task, as these segments did not contain a sufficient number of options or "decisions" to exclude simple chance effects/guessing from contaminating the prediction results.

3. No significant differences between the skill groups were apparent for individual scaling error on the practice trials, $F(1,29)=1.95, p>.05$.

4. One of the expert participants did not undertake the recall and prediction task plus the data of one further expert was omitted from the analysis of prediction accuracy as the participant failed to complete that component of the task as instructed.

5. The cumulative hours from age $6-18$ years shown in Figure $2 \mathrm{~b}$ are slightly different from the total accumulated hours reported in the text because the latter is based on the period up to the player's entry into the AFL, which may be at an age other than 18 years.

6. The large standard deviations observed in this analysis arise because a large number of participants reported $0 \mathrm{hr}$ of deliberate play that was Australian football specific.

\section{References}

Abernethy, B. (1990). Anticipation in squash: Differences in advance cue utilization between expert and novice players. Journal of Sports Sciences, 8, 11-34.

Abernethy, B., Baker, J., \& Côté, J. (2005). Transfer of pattern recall skills may contribute to the development of sports expertise. Applied Cognitive Psychology, 19, 705-718.

Abernethy, B., Farrow, D., \& Berry, J. (2003). Constraints and issues in the development of a general theory of expert perceptual-motor performance: A critique of the Deliberate Practice framework. In J.L. Starkes \& K.A. Ericsson (Eds.), Expert Performance in Sport: Recent Advances in Research on Sport Expertise (pp. 349-369). Champaign, IL: Human Kinetics.

Abernethy, B., Neal, R.J., \& Koning, P.V. (1994). Visual-perceptual and cognitive differences between expert, intermediate, and novice snooker players. Applied Cognitive Psychology, 8, 185-211.

Abernethy, B., \& Russell, D.G. (1987). Expert-novice differences in an applied selective attention task. Journal of Sport Psychology, 9, 326-345.

Allard, F., Graham, S., \& Paarsalu, M.L. (1980). Perception in sport: Basketball. Journal of Sport Psychology, 2, 14-21.

Baker, J., Côté, J., \& Abernethy, B. (2003a). Learning from the experts: Practice activities of expert decision makers in sport. Research Quarterly for Exercise and Sport, 74, 342-347.

Baker, J., Côté, J., \& Abernethy, B. (2003b). Sport-specific practice and the development of expert decision-making in team ball sports. Journal of Applied Sport Psychology, $15,12-25$.

Côté, J. (1999). The influence of the family in the development of talent in sport. The Sport Psychologist, 13, 395-417. 
Côté, J., Baker, J., \& Abernethy, B. (2003). From play to practice: A developmental framework for the acquisition of expertise in team sport. In J. Starkes \& K.A. Ericsson (Eds.), Expert performance in sports: Advances in research on sport expertise (pp. 89-110). Champaign, IL: Human Kinetics.

Côté, J., Baker, J., \& Abernethy, B. (2007). Practice and play in the development of sport expertise. In G. Tenenbaum \& R.C. Eklund (Eds.), Handbook of Sport Psychology (3rd ed., pp. 184-202). Hoboken, NJ: Wiley.

Côté, J., Ericsson, K.A., \& Law, M. (2005). Tracing the development of athletes using retrospective interview methods: A proposed interview and validation procedure for reported information. Journal of Applied Sport Psychology, 17, 1-19.

Côté, J., \& Hay, J. (2002). Children's involvement in sport: A developmental perspective. In J.M. Silva \& D. Stevens (Eds.), Psychological foundations of sport (2nd ed., pp. 484-502). Boston, MA: Merrill.

Côté, J., MacDonald, D., Baker, J., \& Abernethy, B. (2006). When "where" is more important than "when": Birthplace and birthdate effects on the achievement of sporting expertise. Journal of Sports Sciences, 24, 1065-1073.

Deakin, J.M., \& Cobley, S. (2003). An examination of the practice environments in figure skating and volleyball: A search for deliberate practice. In J.L. Starkes \& K.A. Ericsson (Eds.), Expert Performance in Sport: Recent Advances in Research on Sport Expertise (pp. 90-113). Champaign, IL: Human Kinetics.

Dickinson, J. (1978). Retention of intentional and incidental motor learning. Research Quarterly, 49, 437-441.

Ericsson, K.A. (1996). The acquisition of expert performance: An introduction to some of the issues. In K.A. Ericsson (Ed.), The road to excellence: The acquisition of expert performance in the arts, sciences, sports and games (pp. 1-50). Mahwah, NJ: Lawrence Erlbaum.

Ericsson, K.A. (2003). Development of elite performance and deliberate practice: An update from the perspective of the expert performance approach. In J.L. Starkes \& K.A. Ericsson (Eds.), Expert Performance in Sport: Recent Advances in Research on Sport Expertise (pp. 50-81). Champaign, IL: Human Kinetics.

Ericsson, K.A., Krampe, R.T., \& Tesch-Römer, C. (1993). The role of deliberate practice in the acquisition of expert performance. Psychological Review, 100, 363-406.

Ericsson, K.A., \& Simon, H.A. (1993). Protocol analysis: Verbal reports as data (Rev. ed.). Cambridge, MA: The MIT Press.

Farrow, D., Baker, J., \& MacMahon, C. (Eds.). (2007). Developing sport expertise: Researchers and coaches put theory into practice. London: Routledge.

Flanagan, J.C. (1954). The critical incident technique. Psychological Bulletin, 51, 327358.

Helsen, W.F., Hodges, N.J., van Winckel, J., \& Starkes, J.L. (2000). The roles of talent, physical precocity and practice in the development of soccer expertise. Journal of Sports Sciences, 18, 727-736.

Helsen, W.F., Starkes, J.L., \& Hodges, N.J. (1998). Team sports and the theory of deliberate practice. Journal of Sport \& Exercise Psychology, 20, 12-34.

Hodge, T., \& Deakin, J. (1998). Deliberate practice and expertise in the martial arts: The role of context in motor recall. Journal of Sport \& Exercise Psychology, 20, 260279.

Hodges, N.J., \& Starkes, J.L. (1996). Wrestling with the nature of expertise: A sport-specific test of Ericsson, Krampe and Tesch-Römer's (1993) theory of <deliberate practice>. International Journal of Sport Psychology, 27, 400-424.

Kelly, S.W., Burton, A.M., Kato, T., \& Akamatsu, S. (2001). Incidental learning of realworld irregularities. Psychological Science, 12, 86-89. 
Keogh, J. (1999). The use of physical fitness scores and anthropometric data to predict selection in an elite under 18 Australian Rules football team. Journal of Science and Medicine in Sport, 2, 125-133.

Kopelman, M.D., Wilson, B.A., \& Baddeley, A.D. (1989). The autobiographical memory interview: A new assessment of autobiographical and personal semantic memory in amnesic patients. Journal of Clinical and Experimental Neuropsychology, 11, 724744.

Lovett, M. (Ed.). (2001). AFL 2001: The official statistical history of the AFL. Melbourne, Victoria: Australian Football League Record.

MacMahon, C., Helsen, W., Starkes, J.L., \& Weston, M. (2007). Decision-making skills and deliberate practice in elite association football referees. Journal of Sports Sciences, 25, 65-78.

Maxwell, J.P., Masters, R.S.W., \& Eves, F.F. (2000). From novice to no know-how: A longitudinal study of implicit motor learning. Journal of Sports Sciences, 18, 111-120.

McPherson, S.L. (1999a). Expert-novice differences in performance skills and problem representations of youth and adults during tennis competition. Research Quarterly for Exercise and Sport, 70, 233-251.

McPherson, S.L. (1999b). Tactical differences in problem representations and solutions in collegiate varsity and beginner women tennis players. Research Quarterly for Exercise and Sport, 70, 369-384.

Oslin, J., \& Mitchell, S. (1998). An investigation of tactical transfer in net games. Research Quarterly for Exercise and Sport, 69(Suppl.), A-98.

Piaget, J. (1962). Play, dreams and imitation in childhood. New York: W.W. Norton.

Pyne, D.B., Gardner, A.S., Sheehan, K., \& Hopkins, W.G. (2005). Fitness testing and career progression in AFL football. Journal of Science and Medicine in Sport, 8, 321-332.

Schmidt, R.A., \& Lee, T.D. (2005). Motor control and learning (4th ed.). Champaign, IL: Human Kinetics.

Simon, H.A., \& Chase, W.G. (1973). Skill in chess. American Scientist, 61, 394-403.

Smeeton, N., Ward, P., \& Williams, A.M. (2004). Do pattern recognition skills transfer across sports? A preliminary analysis. Journal of Sports Sciences, 22, 205-213.

Soberlak, P., \& Côté, J. (2003). The developmental activities of elite ice hockey players. Journal of Applied Sport Psychology, 15, 41-49.

Starkes, J.L. (1987). Skill in field hockey: The nature of the cognitive advantage. Journal of Sports Psychology, 9, 146-160.

Starkes, J.L. (2000). The road to expertise: Is practice the only determinant? International Journal of Sport Psychology, 31, 431-451.

Starkes, J.L., Deakin, J., Allard, F., Hodges, N.J., \& Hayes, A. (1996). Deliberate practice in sports: What is it anyway? In K.A. Ericsson (Ed.), The road to excellence: The acquisition of expert performance in the arts and sciences, sports, and games (pp. 81-106). Mahwah, NJ: Erlbaum.

Tabachnick, B.G., \& Fidell, L.S. (2001). Using multivariate statistics (4th ed.). Boston, MA: Allyn \& Bacon.

Thorpe, R., Bunker, D., \& Almond, L. (1986). Rethinking games teaching. Loughborough, U.K: Loughborough University Press.

Ward, P., Hodges, N.J., Starkes, J.L., \& Williams, A.M. (2007). The road to excellence: Deliberate practice and the development of expertise. High Ability Studies, 18, 119 153.

Manuscript submitted: July 18, 2007

Revision accepted: July 1, 2008 